Research Article

\title{
The First Step of Health Policy-Making for Lifestyle Modifications at Middle Age: Problem Identification in 40- to 60-Year-Old Population, Northern Iran
}

\author{
Simin Mouodi, ${ }^{1}$ Seyed Reza Hosseini ${ }^{D},{ }^{1}$ Reza Ghadimi, ${ }^{2}$ Ali Bijani ${ }^{(D)}{ }^{1}$ \\ Robert Graham Cumming, ${ }^{3}$ Hassan Ashrafian Amiri, ${ }^{1}$ Fatemeh Bayani, ${ }^{1}$ and Shima Sum ${ }^{1}$ \\ ${ }^{1}$ Social Determinants of Health Research Center, Health Research Institute, Babol University of Medical Sciences, Babol, Iran \\ ${ }^{2}$ Health Research Institute, Babol University of Medical Sciences, Babol, Iran \\ ${ }^{3}$ School of Public Health, University of Sydney, Sydney, NSW, Australia
}

Correspondence should be addressed to Seyed Reza Hosseini; hosseinirezaseyed@gmail.com

Received 18 November 2017; Revised 8 June 2018; Accepted 17 June 2018; Published 16 July 2018

Academic Editor: David H. St-Pierre

Copyright (C) 2018 Simin Mouodi et al. This is an open access article distributed under the Creative Commons Attribution License, which permits unrestricted use, distribution, and reproduction in any medium, provided the original work is properly cited.

Background. The purpose of this study was to determine the current situation of lifestyle behaviors and related outcomes, as the first step to make proper local health policies for improvement of health lifestyle behaviors. Materials and Methods. This analytic research has been conducted as a cross-sectional study on the middle-aged (40-60 years old) population of Amirkola, Northern Iran. The Persian translation of the Health-Promoting Lifestyle Profile II questionnaire and the International Physical Activity Questionnaire were used for data collection. Also, anthropometric variables, blood pressure, fasting blood sugar, and serum lipids profile were examined. Results. Three hundred one individuals have been enrolled in the study. Results showed that $10.6 \%$ of the participants had unhealthy lifestyle behaviors in the subdomain of spiritual growth; $46.8 \%$ in the subdomain of health responsibility; and $48.2 \%$ in the subdomains of stress management, physical activity, and nutrition; men had more physical activity than women $(p<0.001)$. Totally, 189 persons $(63.9 \%)$ had serum cholesterol greater than or equal to $200 \mathrm{mg} / \mathrm{dL}$; seventy-five individuals $(25 \%)$ had high blood pressure. One hundred twenty-six persons $(81.8 \%)$ of women and $103(70.1 \%)$ of men were overweight or obese. Conclusions. Health lifestyle behaviors in 40 - to 60 -year-old population need a proper intervention to improve the current situation.

\section{Introduction}

The increasing prevalence of noncommunicable diseases (NCDs), especially cardiovascular diseases, diabetes, cancer, and chronic respiratory disorders, has driven health policymakers to implement effective programs for prevention and control of these diseases, worldwide [1-3]. These major NCDs share four behavioral risk factors which represent one's lifestyle, namely, tobacco use, unhealthy diet, physical inactivity, and harmful use of alcohol [4]. As lifestyles become more sedentary and diets change more rapidly than ever, these diseases are becoming more common and are striking at a younger age [5]. Recently, greater efforts have been made to best encourage people to have an active living and healthier lifestyle, including making better nutritional patterns and physical activity (PA) choices [6-13]. The World Health Organization (WHO) advocates to all countries, either developed or developing, to make sustainable policies for fighting NCDs, as the most important health threats [1]. The WHO reported that NCDs kill 16 million people each year before their 70th birthdays [1]. Unhealthy diet and lack of physical activity are leading global risks to health [14]. Globally, 1 in 4 adults is not active enough [15]. Worldwide obesity has more than doubled since 1980; in 2014, more than 1.9 billion adults, 18 years and older, were overweight; of these, over 600 million were obese. Thirty-nine percent of adults aged 18 years and above were overweight in 2014, and $13 \%$ were obese [16]. 
Recent studies predicted that disability-adjusted life years related to cardiovascular diseases would be increased more than twofold in 2025 compared with 2005 in Iranian adults aged $\geq 30$ years [17]. The Isfahan Cohort Study conducted in the central part of Iran showed that the incidence rates for almost all cardiovascular diseases were high in adults aged 35 years and above [18]. According to the third national surveillance of risk factors of noncommunicable diseases in Iranian adults (aged 15-64 years), the prevalence of diabetes, hypertension, obesity, central obesity, hypertriglyceridemia, and hypercholesterolemia was reported to be $8.7 \%, 26.6 \%, 22.3 \%, 53.6 \%, 36.4 \%$, and $42.9 \%$, respectively [19]; furthermore, the prevalence of low physical activity was estimated to be $44.8 \%$, and the odds of lower physical activity in the women were three times greater than those in men [20]. The survey of Tehran Lipid and Glucose Study in adult population (aged 30-74 years) over 6 years of follow-up suggested that current situation of noncommunicable disease risk factors needs a proper lifestyle intervention regarding changes in nutritional habits and increased physical activity for primary prevention of cardiovascular diseases in Iranian adults [21, 22].

Considering the importance of novel, local, costeffective, and culturally acceptable interventions to change sedentary lifestyle [23-26] and due to limited published articles related to the adults' lifestyle behaviors in the northern region of Iran, this study aimed to evaluate the current situation of health-promoting lifestyle profile, physical activity, anthropometric variables, and the profile of plasma lipids and glucose in the middle-aged population of Northern Iran, near Caspian Sea. The results can be used as the first step of policy-making to implement proper interventions $[12,27]$ for lifestyle modifications in this region.

\section{Materials and Methods}

This analytic research has been conducted as a crosssectional study on the middle-aged (40-60 years old) population of Amirkola, Northern Iran. Sample size was determined based on data from the previous studies by considering $p=0.5$ and $d=0.06$ for a sample comprising 267 individuals [28]; in addition, taking a possible loss to follow-up into account, a safety margin of $10-15 \%$ was used [29]. Considering that the entire population of this area is covered by the family physician program, we used various methods to invite and recruit middle-aged population, including (1) informing local health care workers and family physicians; (2) public announcements by local health volunteers (nonemployed women who have voluntary cooperation with health centers); (3) distribution of public notices in households, public gathering places, mosques, banks, post offices, local markets, and stores; and (4) selecting the research center in the central part of the city, close to the local health centers, in the access of people of the region and keeping this center active at various times of the morning and evening on Saturdays to Thursdays each week in order to be responsive to the clients. At first, the volunteers who referred to the research center have been checked for exclusion criteria; then, they were divided into 4 groups according to their sex and age (male and female; in the age groups of 40-49 and 50-60 years); at the same time, using the information available about households which were associated with the health centers of the region, the researchers called the households which had at least one person in the age group of 40-60 years and invited them to participate in the study. Simple random sampling was used to select these households. Sampling continued until each of the four groups had nearly the same number of participants. Women in the pregnancy or breast-feeding period, the persons who could not read and write (and could not read the written informed consent form of the study), and those who were undergoing specific nutrition regimens, prescribed by a physician, have been excluded.

The Persian translation of the Health-Promoting Lifestyle Profile II (HPLP-II) questionnaire was used to investigate participants' lifestyles. This questionnaire includes 52 questions in six lifestyle subscales (spiritual growth with "11 questions," health responsibility "13 questions," interpersonal relations "8 questions," stress management "6 items," physical activity "7 questions," and nutritional habits "7 questions"). Each question has a four-point response scale to determine the frequency of that behavior, ranging from 1-4: " 1 " representing "never" and " 4 " representing "routinely." An average of $\geq 2.50$ was considered to be a positive response in each question [30]; therefore, considering the number of questions in each subdomain, the cutoff point for health behaviors related to spiritual growth was considered as 27.5 , health responsibility as 32.5 , interpersonal relations as 20 , stress management as 15 , physical activity, and nutritional habits as 17.5. The HPLP-II instrument has been translated in different languages [31, 32]; validity and reliability of its Iranian version have been confirmed in previous studies [33, 34].

We used the International Physical Activity Questionnaire (IPAQ) to assess physical activity (PA) of the participants. Validity and reliability of its Iranian version have been confirmed in the year 2012 [35]. This questionnaire includes four parts ((1) activities at work; (2) housework, gardening, and caring for family; (3) PA in transportation; and (4) recreation, sport, and leisure time) and asks about the intensity and time a person spent being physically active in the last 7 days. For each domain, participants recorded the number of days and time spent each day undertaking vigorous- and moderate-intensity activities separately along with the time spent walking. Vigorous physical activities are defined as activities that take hard physical effort and make a person breathe much harder than normal such as lifting heavy things, digging, heavy construction work, or climbing stairs, and moderate activities are defined as activities that take moderate physical effort and make them breathe somewhat harder than normal such as carrying light loads. These values (vigorous activity, moderate activity, and walking) were used to calculate the PA levels, as specified in the official IPAQ instruction manual. Each type of activity was weighted by its energy requirements as MET (metabolic equivalent of task). By multiplying MET value of particular activity (3.3 METs for walking, 4.0 METs for moderate PA, and 8.0 METs for vigorous PA), total MET minutes per week 
was calculated. Vigorous and moderate activities were defined as those lasting for at least 10 minutes continuously [35]. Questions related to time spent sitting on a weekday or weekend were excluded from analysis. Study population was classified into the levels of PA according to MET minutes/week: "minimally active" for individuals who achieved a minimum of at least $600 \mathrm{MET}$ minutes/week, "highly active" for those who had a minimum of at least 1500 MET minutes per week, and "inactive" persons for those who had not met the above two categories [36].

Other data which were collected included age, gender, education level, occupation, marital status, living region (urban or rural), and history of comorbid physical or mental disorders. Also, weight and height, blood pressure, fasting blood sugar, and serum lipids profile were examined. Body mass index (BMI) was calculated as weight (in kilograms)/height ${ }^{2}$ (in meters).

Other anthropometric measures which have been assessed included body fat percentage and waist and buttock circumferences. These variables have been measured with a tape. Also, waist-to-hip ratio (WHR) and waist-to-height ratio (WHtR) $[37,38]$ have been calculated.

Waist circumference was measured around the midpoint between the lower margin of the last palpable rib and the top of the iliac crest, and buttock measurement was taken at the maximum circumference over the buttocks. All measurements were taken once over light clothing, and values were recorded in centimeters.

Body fat percentage was measured by using the hand-tofoot bioelectrical impedance analysis technique with a digital body fat calculator (BF511 model; Omron company). This technique has been reported as a simple, quick, and noninvasive method which can give reliable measurements of body composition with minimal intra- and interobserver variability; the results are available immediately and reproducible with $<1 \%$ error on repeated measurements [39].

Blood pressure was measured with the participant in the sitting position, using a digital sphygmomanometer (Omron M6 brand), and the average of two times blood pressure measurement $\geq 140 / 90 \mathrm{mmHg}$ was defined as hypertension. Early morning venous blood samples $(5 \mathrm{~mL})$ were collected after fasting for at least 12 hours to assess fasting blood sugar (FBS), total cholesterol, high-density lipoprotein (HDL) cholesterol, low-density lipoprotein (LDL) cholesterol, and triglyceride (TG) levels; these values were measured using Pars Azmoon kits via the autoanalyzer respons ${ }^{\circledR 9} 910$ DiaSys system. All of the laboratory tests have been conducted in a particular laboratory which had undertaken external quality control.

According to the National Cholesterol Education Program Adult Treatment Panel III Report [37], cutoff points for fasting blood glucose, total serum cholesterol, triglyceride, and LDL levels have been considered less than 126, 200,150 , and $100 \mathrm{mg} / \mathrm{dL}$, respectively. The HDL cholesterol cutoff point was considered less than $40 \mathrm{mg} / \mathrm{dL}$ in men and less than $50 \mathrm{mg} / \mathrm{dL}$ in women. Also, serum TG levels in the range of 150-199 were classified as borderline-high TG, $200-499$ as high TG, and $>500 \mathrm{mg} / \mathrm{dL}$ as very high TG categories.
Data analysis was performed by SPSS 17 package; the chi-square test, Fisher's exact test, and $t$-test were used for data analysis with a significance level of $p<0.05$. The Kolmogorov-Smirnov test was used to evaluate the normal distribution of quantitative data.

All of the participants signed a written informed consent form. They have been assured that their information would be kept confidential. This research has been approved by the Ethics Committee of Babol University of Medical Sciences as registration code Mubabol.Rec.1394.45.

\section{Results}

Three hundred one individuals have been enrolled in this study. The mean age of the participants was $49.67 \pm 5.42$ (range of 40-60 years); 154 persons (51.2\%) were female with the mean age of $49.0 \pm 5.13$ years, and 147 (48.8\%) were male with the mean age of $50.4 \pm 5.64$. Basic characteristics of the participants divided into the two age groups are presented in Table 1. This table shows that these two age groups had no significant difference in their baseline characteristics $(p>0.05)$, except in their occupation $(p=0.047)$.

Lifestyle behaviors according to the HPLP-II questionnaire are presented in Table 2. Thirty-two participants (10.6\%) in the subdomain of spiritual growth, 141 participants (46.8\%) in the subdomain of health responsibility, 145 participants (48.2\%) in the subdomain of interpersonal relations, and 145 participants (48.2\%) in the subdomains of stress management, physical activity, and nutrition had scores less than average. There was no significant difference between the two age groups about distribution of the average score of lifestyle behaviors except in the nutrition subscale $(p=0.033)$; the age group of 50-60 years had higher scores in this subscale. Men and women had no significant difference in the total score and subdomains of lifestyle behavior $(p>0.05)$ except in the subdomain of health responsibility $(p<0.001)$; in this subscale, women had higher scores.

Distribution of PA in two sexes divided into the two age groups is presented in Table 3. Totally, 24 women (15.6\%) and 1 man $(0.7 \%)$ were inactive, 36 women $(23.4 \%)$ and 13 men $(8.8 \%)$ were minimally active, and 94 women $(61.0 \%)$ and 133 men (90.5\%) were highly active according to MET $\mathrm{min} /$ week. A significant statistical difference was observed between two sexes about their physical activity $(p<0.001)$; men had more physical activity than women.

Anthropometric measures, blood pressure, fasting blood sugar, and serum lipids profile of the participants divided into two age groups are presented in Table 4. This table shows that these two age groups have significant differences in height, waist circumference, WHR, WHtR, and systolic blood pressure $(p<0.05)$. We found significant differences in mean systolic blood pressure, BMI, body fat percentage, waist and buttock circumferences, WHR, WHtR, fasting blood glucose, and TG and HDL serum levels between male and female persons $(p<0.05)$. Mean systolic blood pressure and waist circumference, WHR, WTR, fasting blood glucose, and TG serum level were higher in men; BMI, body fat percentage, buttock circumference, WHtR, and HDL were higher in women. 
TABle 1: Basic descriptive characteristics of the participants.

\begin{tabular}{|c|c|c|c|c|}
\hline \multirow{2}{*}{ Variables } & \multicolumn{2}{|c|}{ Age groups } & \multirow[b]{2}{*}{ Total $(N=301), n(\%)$} & \multirow[b]{2}{*}{$p$ value } \\
\hline & $40-49$ years $(N=145), n(\%)$ & $50-60$ years $(N=156), n(\%)$ & & \\
\hline \multicolumn{5}{|l|}{ Education level } \\
\hline Less than diploma & $88(60.7)$ & $89(57.1)$ & $177(58.8)$ & \multirow{3}{*}{0.408} \\
\hline Diploma & $37(25.5)$ & $50(32.1)$ & $87(28.9)$ & \\
\hline Higher than diploma & $20(13.8)$ & $17(10.9)$ & $37(12.3)$ & \\
\hline \multicolumn{5}{|l|}{ Occupation } \\
\hline Shopkeepers & $7(4.8)$ & $5(3.2)$ & $12(4.0)$ & \multirow{4}{*}{0.047} \\
\hline Housewives & $72(49.7)$ & $63(40.4)$ & $135(44.9)$ & \\
\hline Employees & $18(12.4)$ & $31(19.9)$ & $49(16.3)$ & \\
\hline Others & $48(33.1)$ & $57(36.5)$ & $105(34.9)$ & \\
\hline \multicolumn{5}{|l|}{ Marital status } \\
\hline Married & $140(96.6)$ & $146(93.6)$ & $286(95.0)$ & \multirow{2}{*}{0.066} \\
\hline Single, divorced, or widowed & $5(3.4)$ & $10(6.4)$ & $15(5.0)$ & \\
\hline \multicolumn{5}{|l|}{ Living region } \\
\hline Urban & $142(97.9)$ & $150(96.2)$ & $292(97.0)$ & \multirow{2}{*}{0.288} \\
\hline Rural & $3(2.1)$ & $6(3.8)$ & $9(3.0)$ & \\
\hline \multicolumn{5}{|c|}{ Past medical history of physical disorders } \\
\hline No & $118(81.4)$ & $117(75.0)$ & $235(78.1)$ & \multirow{2}{*}{0.181} \\
\hline Yes & $27(18.6)$ & $39(25.0)$ & $66(21.9)$ & \\
\hline \multicolumn{5}{|c|}{ Past medical history of mental disorders } \\
\hline No & $142(97.9)$ & $146(93.6)$ & $288(95.7)$ & \multirow{2}{*}{0.064} \\
\hline Yes & $3(2.1)$ & $10(6.4)$ & $13(4.3)$ & \\
\hline
\end{tabular}

TABLe 2: Distribution of the average score of lifestyle behaviors according to the HPLP-II questionnaire.

\begin{tabular}{lccc}
\hline \multirow{2}{*}{ Lifestyle subdomains } & \multicolumn{2}{c}{ Mean score of lifestyle subdomains in two age groups } & Total mean \pm SD (min-max) \\
& $40-49$ years $(N=145)$ & $50-60$ years $(N=156)$ & $33.81 \pm 5.13(16-44)$ \\
\hline Spiritual growth & $33.81 \pm 5.31$ & $33.81 \pm 4.98$ & $33.38 \pm 7.38(16-51)$ \\
Health responsibility & $34.11 \pm 7.38$ & $32.70 \pm 7.34$ & $23.81 \pm 4.27(10-32)$ \\
Interpersonal relations & $23.87 \pm 4.57$ & $23.76 \pm 4.00$ & $13.67 \pm 2.97(7-22)$ \\
Stress management & $13.76 \pm 3.07$ & $13.59 \pm 2.88$ & $13.01 \pm 4.75(7-28)$ \\
Physical activity & $12.99 \pm 4.67$ & $13.03 \pm 4.84$ & 0.097 \\
Nutrition & $20.12 \pm 3.32$ & $20.63 \pm 3.04$ & 0.620 \\
Total score & $138.65 \pm 19.80$ & $137.51 \pm 18.63$ & $138.06 \pm 19.18(88-191)$ \\
\hline
\end{tabular}

TABLE 3: Distribution of physical activity in men and women within age groups of 40-49 and 50-60 years.

\begin{tabular}{|c|c|c|c|c|c|c|}
\hline \multirow{3}{*}{ IPAQ parameters } & \multicolumn{6}{|c|}{ Mean \pm SD of IPAQ parameters in the two age groups (MET min/week) } \\
\hline & \multicolumn{3}{|c|}{ 40-49 years } & \multicolumn{3}{|c|}{$50-60$ years } \\
\hline & Female $(N=79)$ & Male $(N=66)$ & $p$ value & Female $(N=75)$ & Male $(N=81)$ & $p$ value \\
\hline Walking & $755.9 \pm 974.5$ & $4033.3 \pm 40.39 .2$ & $<0.001$ & $924.9 \pm 834.4$ & $2901.4 \pm 3145.8$ & $<0.001$ \\
\hline Moderate activity & $1889.1 \pm 2112.9$ & $2850.3 \pm 3383.1$ & 0.039 & $1782.4 \pm 2602.0$ & $4395.3 \pm 5650.7$ & $<0.001$ \\
\hline Vigorous activity & $209.1 \pm 1008.2$ & $992.1 \pm 2397.2$ & 0.009 & $336.5 \pm 2026.0$ & $1514.6 \pm 3470.2$ & $<0.001$ \\
\hline Total physical activity & $2854.1 \pm 3143.0$ & $7875.7 \pm 5625.9$ & $<0.001$ & $3043.8 \pm 3503.0$ & $8811.3 \pm 7550.6$ & $<0.001$ \\
\hline
\end{tabular}

In this research, we found 19 individuals $(6.4 \%)$ with FBS greater than or equal to $126 \mathrm{mg} / \mathrm{dL}$ : 5 (3.3\%) of women and $14(9.7 \%)$ of men; 189 persons (63.9\%) with serum cholesterol greater than or equal to $200 \mathrm{mg} / \mathrm{dL}$ : $93(61.6 \%)$ of women and $96(66.2 \%)$ of men; 58 persons (19.6\%) with borderline-high TG, 79 persons (26.7\%) with high TG; and 6 persons $(2.0 \%)$ with very high TG levels. One hundred thirteen $(74.3 \%)$ of women and $126(86.9 \%)$ of men had normal HDL levels $(p=0.006)$, and 85 persons
(28.6\%) had LDL cholesterol less than or equal to $100 \mathrm{mg} / \mathrm{dL}$. Fifty-one subjects (17.0\%) had systolic blood pressure greater than or equal to $140 \mathrm{mmHg}, 55$ persons (18.3\%) had diastolic blood pressure greater than or equal to $90 \mathrm{mmHg}$, and totally 75 individuals (25\%) had high blood pressure.

Relative distribution of body mass index categories in two sexes is presented in Figure 1. Nobody has BMI less than $18.5 \mathrm{~kg} / \mathrm{m}^{2}$ in this study. One hundred twenty-six persons 
TABle 4: Anthropometric variables, blood pressure, fasting blood sugar, and serum lipids profile of the participants.

\begin{tabular}{|c|c|c|c|c|}
\hline \multirow{2}{*}{ Variables } & \multicolumn{2}{|c|}{ Age groups } & \multirow{2}{*}{ Total mean \pm SD $(\min -\max )$} & \multirow{2}{*}{$p$ value } \\
\hline & $40-49$ years $(N=145)$ & $50-60$ years $(N=156)$ & & \\
\hline BMI $\left(\mathrm{kg} / \mathrm{m}^{2}\right)$ & $28.2 \pm 4.6$ & $28.3 \pm 4.2$ & $28.3 \pm 4.4(19.2-46.5)$ & 0.773 \\
\hline Body fat percentage & $32.3 \pm 9.3$ & $30.9 \pm 11.2$ & $31.6 \pm 10.3(5.1-52.2)$ & 0.240 \\
\hline Waist circumference $(\mathrm{cm})$ & $93.4 \pm 10.4$ & $95.7 \pm 8.7$ & $94.6 \pm 9.6(70.0-123.0)$ & 0.032 \\
\hline Buttock circumference $(\mathrm{cm})$ & $108.0 \pm 8.8$ & $107.1 \pm 8.7$ & $107.6 \pm 8.7(88.5-138.0)$ & 0.372 \\
\hline WHR & $0.86 \pm 0.07$ & $0.89 \pm 0.06$ & $0.88 \pm 0.07(0.71-1.09)$ & $<0.001$ \\
\hline WHtR & $0.56 \pm 0.06$ & $0.58 \pm 0.06$ & $0.57 \pm 0.60(0.42-0.76)$ & 0.001 \\
\hline Systolic blood pressure (mmHg) & $121.2 \pm 15.4$ & $128.4 \pm 16.9$ & $124.9 \pm 16.6(88-186)$ & $<0.001$ \\
\hline Diastolic blood pressure $(\mathrm{mmHg})$ & $80.0 \pm 9.9$ & $81.1 \pm 10.5$ & $80.6 \pm 10.3(47-122)$ & 0.347 \\
\hline $\mathrm{FBS}(\mathrm{md} / \mathrm{dL})$ & $95.5 \pm 25.9$ & $100.8 \pm 34.5$ & $98.3 \pm 30.8(60-330)$ & 0.139 \\
\hline Total cholesterol (mg/dL) & $212.0 \pm 48.0$ & $219.8 \pm 44.9$ & $216.1 \pm 46.5(115-457)$ & 0.149 \\
\hline $\mathrm{TG}(\mathrm{mg} / \mathrm{dL})$ & $186.3 \pm 138.9$ & $162.7 \pm 92.3$ & $173.9 \pm 117.0(37-1108)$ & 0.084 \\
\hline $\mathrm{HDL}(\mathrm{mg} / \mathrm{dL})$ & $55.9 \pm 15.7$ & $58.4 \pm 14.1$ & $57.2 \pm 14.9(21-117)$ & 0.149 \\
\hline $\mathrm{LDL}(\mathrm{mg} / \mathrm{dL})$ & $113.2 \pm 30.0$ & $119.1 \pm 26.9$ & $116.3 \pm 28.6(47-233)$ & 0.075 \\
\hline
\end{tabular}

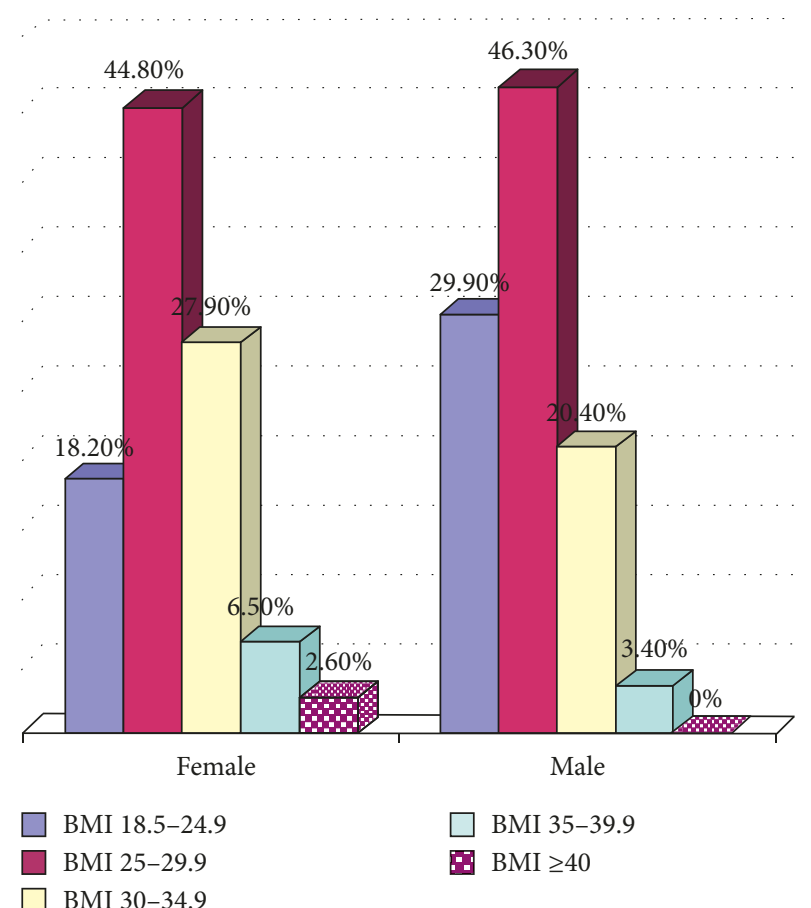

FIgURE 1: Body mass index distribution in two sexes.

(81.8\%) of women and $103(70.1 \%)$ of men were overweight or obese.

\section{Discussion}

We found that $10.6 \%$ of 40 - to 60 -year-old adults had unhealthy lifestyle behaviors in the subdomain of spiritual growth; $46.8 \%$ in the subdomain of health responsibility; and $48.2 \%$ in the subdomains of stress management, physical activity, and nutrition. This finding shows that interventional approaches for improvement of health-promoting behaviors in this region should primarily focus on stress management skills, physical activity, and healthy nutrition program. In the research performed by Enjezab et al. in Yazd, the central part of Iran, in which 483 middle-aged women were assessed, spiritual growth and physical activity subdomains had the highest and the lowest scores, respectively [40]; the research done by Mirghafourvand et al. in Tabriz, the northwest part of Iran, in which 322 infertile couples were examined, showed that the highest mean score was for the nutrition subscale and the lowest was for physical activity and health responsibility subscales in both men and women [41]; in another research conducted by Mirghafourvand et al., women in reproductive age scored highest in interpersonal relations and lowest in physical activity [42]. In the research carried out by Kim et al. in the United Arab Emirates which evaluated healthpromoting lifestyle behaviors among Arabs and Koreans, spiritual growth and interpersonal relations had the highest scores; Arabs scored low on physical activity, and Koreans scored low on health responsibility [43]. These differences in health lifestyle behaviors can be related to ethnic characteristics, cultural variations, and the properties of the population under study which can have impact on the results.

In our study, the 50- to 60-year-old participants had higher scores in the nutrition subscale of the HPLP-II questionnaire; also, women had higher scores in the subdomain of health responsibility. These results show that we should pay more attention to dietary patterns of young adults and should implement interventional plans to encourage men to improve their health care. Okubo et al. reported in their study that older people tended to pay more attention to their diets than younger adults [44]. Vlassoff reported that gender is an important factor which can influence the determinants and consequences of health and illness. He suggested the involvement of both men and women in health education and interventions for promotion of health lifestyles [45], and Bertakis et al. reported that women had a significantly higher number of visits to their primary care clinic and diagnostic services than men. In their study, mean charges for primary care, specialty care, emergency treatment, and diagnostic services and annual total charges were higher for women than men [46].

In this study, nearly $16 \%$ of women were inactive and $23.4 \%$ of them were minimally active, and men had more physical activity than women. The World Health Organization recommends that adults aged 18-64 should do at 
least 150 minutes of moderate-intensity aerobic PA or do at least 75 minutes of vigorous-intensity PA throughout the week or an equivalent combination of moderate- and vigorous-intensity activity. This organization advices that, for additional health benefits, adults should increase their moderate-intensity PA to 300 minutes per week or engage in 150 minutes of vigorous-intensity aerobic PA per week [47]; therefore, considering the results, we should implement interventional programs to improve PA in 40- to 60-year-old population, especially for women. In the research done by Asgari et al. in Iran, 32.5\% of study population aged 15-64 years did exercise at least 10 minutes in their free time [48], and in the research performed by Jurakić et al., conducted on 1032 Croatians aged 15 years and above, the lowest physical activity was found in the 15-24 age group (42.7 MET hours/week) and the highest in the 55-64 age group (72.0 MET hours/week); they reported that the majority of participants (74\%) reached the level of at least 30 minutes of moderate physical activity 5 days a week, which is considered as the lowest level of physical activity for achieving health benefits [49]. In a systematic review conducted to explore the PA patterns among South Asian adults, the overall prevalence of inactivity was reported as follows: India 18.5\%-88.4\%, Pakistan 60.1\%, and Sri Lanka 11.0\%-31.8\% [50]. In the research of Anjana et al. which was conducted among individuals aged $\geq 20$ years in four regions of India, similar to the results of our study, men were significantly more active than women [51]. Yates et al. evaluated differences in levels of PA between white and South Asian populations in Leicestershire, UK. They showed that South Asian participants self-reported less moderate-intensity to vigorous-intensity PA (30 versus $51 \mathrm{~min} /$ day) and walking (11 versus $17 \mathrm{~min} /$ day) [52]. Considering a wide variation in the prevalence of physical inactivity within and between countries [50], these differences in the results can be justifiable.

Mean systolic blood pressure, waist circumference, WHR, WTR, fasting blood glucose, and TG serum level were higher in men; BMI, body fat percentage, buttock circumference, WHtR, and HDL were higher in women. In this research, $6.4 \%$ of the participants had FBS $\geq 126 \mathrm{mg} / \mathrm{dL}$; $63.9 \%$ had serum cholesterol $\geq 200 \mathrm{mg} / \mathrm{dL}$; and $19.6 \%$ had borderline-high TG, $26.7 \%$ high TG, and $2.0 \%$ had very high TG levels. Nine percent of study population had HDL $<40 \mathrm{mg} / \mathrm{dL}$, and nearly $29 \%$ had LDL $\leq 100 \mathrm{mg} / \mathrm{dL}$. Almost twenty-five percent of the persons had blood pressure $\geq 140 / 90 \mathrm{mmHg}$. Seventy-six percent of 40 - to 60 -year-old adults were overweight or obese (BMI $\geq 25)$.

In the research of Asgari et al. in Iran, $7.7 \%$ were diabetics and $25.2 \%$ were hypertensive at the age of 25-64 years. Obesity, overweight, and hypercholesterolemia were $14.8,28.6$, and 15.1, respectively, at the age of 15-64 years [48]. In the research of Bakhshi et al. in Iran, $22.3 \%$ of the adults aged $\geq 15$ years in all provinces of this country were reported obese. Among all racial/ethnic groups, the highest prevalence value was observed in Turk/Gilak/Lor/Turkmen Iranian ethnicities group (25.5\%) [53]. In the research of Krishna Kumar Aryal in Nepal among 15- to 69-year-old population, $21 \%$ were overweight or obese. The prevalence of raised blood pressure and raised blood glucose including those on medication was $26 \%$ and $4 \%$, respectively; also, almost $23 \%$ of study population had raised total cholesterol (total cholesterol $\geq 190 \mathrm{mg} / \mathrm{dL}$ or under current medication for raised cholesterol). The World Health Organization advices to all countries to implement proper policies to reduce modifiable risk factors for NCDs and underlying social determinants through creation of health-promoting environments [4]. We should have policy options in our region to improve health lifestyle behaviors and control the current situation of NCD-related risk factors.

The most important strength of our research was evaluation of NCD-related risk factors in a population-based sample.

We did not take into account some of the behaviors such as alcohol, tobacco, and substance abuse which we did not intend to enter in this study, and this can be considered as a limitation of this research.

\section{Conclusion}

Health lifestyle behaviors in 40 - to 60 -year-old population need a proper intervention to improve the current situation.

\section{Conflicts of Interest}

The authors have no potential conflicts of interest.

\section{Acknowledgments}

The financial support of the Vice Chancellor for Research and Technology of Babol University of Medical Sciences and the kind cooperation of the middle-aged population of Amirkola to participate in this project are greatly appreciated.

\section{References}

[1] M. Chan and M. R. Bloomberg, Political Will Need to Win Fight against Noncommunicable Diseases, World Health Organization, Geneva, Switzerland, 2016, http://www.who. int/mediacentre/commentaries/political-noncommunicablediseases/en.

[2] G. El-Kassas and F. Ziade, "Exploration of the dietary and lifestyle behaviors and weight status and their self-perceptions among Health Sciences University students in North Lebanon," BioMed Research International, vol. 2016, Article ID 9762396, 14 pages, 2016.

[3] W. C. Willett, J. P. Koplan, R. Nugent, C. Dusenbury, P. Puska, and T. A. Gaziano, "Prevention of chronic disease by means of diet and lifestyle changes," in Disease Control Priorities in Developing Countries, J. G. B. D. T. Jamison, A. R. Measham, and G. Alleyne, Eds., The International Bank for Reconstruction and Development/The World Bank, Washington, DC, USA, 2nd edition, 2006.

[4] World Health Organization, Global Action Plan for the Prevention and Control of NCDs 2013-2020, World Health Organization, Geneva, Switzerland, 2013.

[5] C. Hancock, Review the Benefits of Physical Activity for Health and Well-Being, C3 Collaborating for Health, London, UK, 2012.

[6] P. Bully, A. Sánchez, E. Zabaleta-Del-Olmo, H. Pombo, and G. Grandes, "Evidence from interventions based on theoretical models for lifestyle modification (physical activity, diet, alcohol 
and tobacco use) in primary care settings: a systematic review," Preventive Medicine, vol. 76, pp. S76-S93, 2015.

[7] Y. Ye, W. Zhong, X. Lin et al., "Association between sedentary life style and risks of metabolic syndrome and diabetes mellitus type 2," Zhonghua Liu Xing Bing Xue Za Zhi, vol. 35, no. 11, pp. 1235-1240, 2014, in Chinese.

[8] C. Julia, S. Péneau, V. A. Andreeva et al., "Weight-loss strategies used by the general population: how are they perceived?," PLoS One, vol. 9, no. 5, Article ID e97834, 2014.

[9] M. Ezzati and E. Riboli, "Behavioral and dietary risk factors for noncommunicable diseases," New England Journal of Medicine, vol. 369, pp. 954-964, 2013.

[10] A. S. Page and B. M. Winklhofer-Roob, "Five-minutes-totwelve for implementation of early changes in dietary and lifestyle behaviour across Europe," International Journal of Obesity, vol. 35, no. 1, pp. S1-S2, 2011.

[11] G. Claire, "Obesity: effectiveness of a brief physician intervention," Nature Reviews Endocrinology, vol. 13, no. 1, p. 5, 2017.

[12] I. A. Macdonald and R. Atkinson, "Public health initiatives in obesity prevention: the need for evidence-based policy," International Journal of Obesity, vol. 35, no. 4, p. 463, 2011.

[13] T. A. Wadden, V. L. Webb, C. H. Moran, and B. A. Bailer, "Lifestyle modification for obesity: new developments in diet, physical activity, and behavior therapy," Circulation, vol. 125, no. 9, pp. 1157-1170, 2012.

[14] World Health Organization, Healthy Diet. Fact Sheet No. 394, World Health Organization, Geneva, Switzerland, 2015, http://www.who.int/mediacentre/factsheets/fs394/en.

[15] World Health Organization, Physical Activity. Fact Sheet No. 385, World Health Organization, Geneva, Switzerland, 2017, http://www.who.int/mediacentre/factsheets/fs385/en.

[16] World Health Organization, Obesity and Overweight. Fact Sheet No. 311, World Health Organization, Geneva, Switzerland, 2016, http://www.who.int/mediacentre/factsheets/ fs $311 /$ en.

[17] M. Sadeghi, A. A. Haghdoost, A. Bahrampour, and M. Dehghani, "Modeling the burden of cardiovascular diseases in Iran from 2005 to 2025: the impact of demographic changes," Iranian Journal of Public Health, vol. 46, no. 4, pp. 506-516, 2017.

[18] M. Talaei, N. Sarrafzadegan, M. Sadeghi et al., "Incidence of cardiovascular diseases in an Iranian population: the Isfahan Cohort Study," Archives of Iranian Medicine, vol. 16, no. 3, pp. 138-144, 2013.

[19] A. Esteghamati, A. Meysamie, O. Khalilzadeh et al., "Third national surveillance of risk factors of non-communicable diseases (SuRFNCD-2007) in Iran: methods and results on prevalence of diabetes, hypertension, obesity, central obesity, and dyslipidemia," BMC Public Health, vol. 9, no. 1, p. 167, 2009.

[20] H. Fakhrzadeh, S. Djalalinia, M. Mirarefin et al., "Prevalence of physical inactivity in Iran: a systematic review," Journal of Cardiovascular and Thoracic Research, vol. 8, no. 3, pp. 92-97, 2016.

[21] S. Ebrahimof, F. Hosseini-Esfahani, P. Mirmiran, M. FallahKezabi, and F. Azizi, "Food Patterns and Framingham Risk Score in Iranian adults: Tehran Lipid and Glucose Study: 2005-2011," Metabolic Syndrome and Related Disorders, vol. 16, no. 1, pp. 64-71, 2018.

[22] F. Azizi, "Tehran lipid and glucose study: a legacy for prospective community-based research," Archives of Iranian Medicine, vol. 17, no. 6, pp. 392-393, 2014.
[23] W. V. Brown, H. E. Bays, R. La Forge, and G. Sikand, "JCL roundtable: gender differences in risk reduction with lifestyle changes," Journal of Clinical Lipidology, vol. 9, no. 4, pp. 486-495, 2015.

[24] N. Mastellos, L. H. Gunn, L. M. Felix, J. Car, and A. Majeed, "Transtheoretical model stages of change for dietary and physical exercise modification in weight loss management for overweight and obese adults," Cochrane Database of Systematic Reviews, vol. 5, no. 2, article CD008066, 2014.

[25] M. Razavi, S. Fournier, D. S. Shepard, G. Ritter, G. K. Strickler, and W. B. Stason, "Effects of lifestyle modification programs on cardiac risk factors," PLoS One, vol. 9, no. 12, Article ID e114772, 2014.

[26] H. A. Tagoe and F. A. A. Dake, "Healthy lifestyle behaviour among Ghanaian adults in the phase of a health policy change," Globalization and Health, vol. 7, no. 1, p. 7, 2011.

[27] World Health Organization, Module 5: Understanding Health Policy Processes, World Health Organization, Geneva, Switzerland, 2005, http://www.who.int/hac/techguidance/ tools/disrupted_sectors/adhsm_mod5_en.

[28] K. Hajian-Tilaki, "Sample size estimation in epidemiologic studies," Caspian Journal of Internal Medicine, vol. 2, no. 4, pp. 289-298, 2011.

[29] L. Jahangiry, D. Shojaeizadeh, A. Montazeri, M. Najafi, K. Mohammad, and M. Yaseri, "Adherence and attrition in a web-based lifestyle intervention for people with metabolic syndrome," Iranian Journal of Public Health, vol. 43, no. 9, pp. 1248-1258, 2014.

[30] S. Zhang, F. Tao, A. Ueda, C. Wei, and J. Fang, "The influence of health-promoting lifestyles on the quality of life of retired workers in a medium-sized city of Northeastern China," Environmental Health and Preventive Medicine, vol. 18, no. 6, pp. $458-465,2013$

[31] C. N. Wei, K. Harada, K. Ueda, K. Fukumoto, K. Minamoto, and A. Ueda, "Assessment of health-promoting lifestyle profile in Japanese university students," Environmental Health and Preventive Medicine, vol. 17, no. 3, pp. 222-227, 2012.

[32] I. L. Mullins, T. O’Day, and T. Y. Kan, "Validation of the Health-Promoting Lifestyle Profile II for Hispanic male truck drivers in the Southwest," Clinical Nursing Research, vol. 22, no. 3, pp. 375-394, 2013.

[33] P. T. Tanjani, M. Azadbakht, G. Garmaroudi, R. Sahaf, and Z. Fekrizadeh, "Validity and reliability of Health Promoting Lifestyle Profile II in the Iranian elderly," International Journal of Preventive Medicine, vol. 7, no. 1, p. 74, 2016.

[34] I. Mohammadi Zeidi, A. Pakpour Hajiagha, and B. Mohammadi Zeidi, "Reliability and validity of Persian version of the Health-Promoting Lifestyle Profile," Journal of Mazandaran University of Medical Sciences, vol. 22, no. 1, pp. 103-113, 2012.

[35] M. H. Baghiani Moghaddam, F. Bakhtari Aghdam, M. Asghari Jafarabadi et al., "The Iranian version of International Physical Activity Questionnaire (IPAQ) in Iran: content and construct validity, factor structure, internal consistency and stability," World Applied Sciences Journal, vol. 18, no. 8, pp. 1073-1080, 2012.

[36] IPAQ Instruction Office, Guidelines for Data Processing and Analysis of the International Physical Activity Questionnaire (IPAQ)-Short Form, IPAQ Instruction Office, Barcelona, Spain, 2004, http://www.institutferran.org/documentos/ scoring_short_ipaq_april04.

[37] National Cholesterol Education Program (NCEP) Expert Panel on Detection, Evaluation, and Treatment of High Blood 
Cholesterol in Adults (Adult Treatment Panel III), "Third report of the National Cholesterol Education Program (NCEP) expert panel on detection, evaluation, and treatment of high blood cholesterol in adults (adult treatment panel III) final report," Circulation, vol. 106, no. 25, pp. 3143-3421, 2002.

[38] D. D. Reidpath, J. C. Cheah, F. C. Lam, S. Yasin, I. Soyiri, and P. Allotey, "Validity of self-measured waist and hip circumferences: results from a community study in Malaysia," Nutrition Journal, vol. 12, no. 1, p. 135, 2013.

[39] M. Dehghan and A. T. Merchant, "Is bioelectrical impedance accurate for use in large epidemiological studies?," Nutrition Journal, vol. 7, no. 1, p. 26, 2008.

[40] B. Enjezab, Z. Farajzadegan, F. Taleghani, A. Aflatoonian, and M. A. Morowatisharifabad, "Health promoting behaviors in a population-based sample of middle-aged women and its relevant factors in Yazd, Iran," International Journal of Preventive Medicine, vol. 3, no. 1, pp. S191-S198, 2012.

[41] M. Mirghafourvand, F. Sehhati, and M. Rahimi, "Healthpromoting lifestyle and its demographic predictors in infertile couples referred to infertility clinic of Tabriz Al-Zahra Hospital, 2013," Journal of Caring Sciences, vol. 3, no. 3, pp. 175-184, 2014.

[42] M. Mirghafourvand, A. Baheiraei, S. Nedjat, E. Mohammadi, S. M. Charandabi, and R. Majdzadeh, "A population-based study of health-promoting behaviors and their predictors in Iranian women of reproductive age," Health Promotion International, vol. 30, no. 3, pp. 586-594, 2015.

[43] H. J. Kim, S. Choi-Kwon, H. Kim, Y. H. Park, and C. K. Koh, "Health-promoting lifestyle behaviors and psychological status among Arabs and Koreans in the United Arab Emirates," Research in Nursing and Health, vol. 38, no. 2, pp. 133-141, 2015.

[44] H. Okubo, S. Sasaki, K. Murakami et al., "Designing optimal food intake patterns to achieve nutritional goals for Japanese adults through the use of linear programming optimization models," Nutrition Journal, vol. 14, no. 1, p. $57,2015$.

[45] C. Vlassoff, "Gender differences in determinants and consequences of health and illness," Journal of Health, Population and Nutrition, vol. 25, no. 1, pp. 47-61, 2007.

[46] K. D. Bertakis, R. Azari, L. J. Helms, E. J. Callahan, and J. A. Robbins, "Gender differences in the utilization of health care services," Journal of Family Practice, vol. 49, no. 2, pp. 147-152, 2000.

[47] World Health Organization, Global Recommendations on Physical Activity for Health, WHO, Geneva, Switzerland, 2010, http://whqlibdoc.who.int/publications/2010/9789241599979.

[48] F. Asgari, H. Aghajani, M. Haghazali, and H. Heidarian, "Non-communicable diseases risk factors surveillance in Iran," Iranian Journal of Public Health, vol. 38, no. 1, pp. 119-122, 2009.

[49] D. Jurakić, Z. Pedišić, and M. Andrijašević, "Physical activity of Croatian population: cross-sectional study using International Physical Activity Questionnaire," Croatian Medical Journal, vol. 50, pp. 165-173, 2009.

[50] C. D. Ranasinghe, P. Ranasinghe, R. Jayawardena, and A. Misra, "Physical activity patterns among South-Asian adults: a systematic review," International Journal of Behavioral Nutrition and Physical Activity, vol. 10, no. 1, p. 116, 2013.

[51] R. M. Anjana, R. Pradeepa, A. K. Das et al., "Physical activity and inactivity patterns in India-results from the ICMRINDIAB study (Phase-1) [ICMR-INDIAB-5]," International Journal of Behavioral Nutrition and Physical Activity, vol. 11, no. 1, p. 26, 2014.
[52] T. Yates, J. Henson, C. Edwardson, D. H. Bodicoat, M. J. Davies, and K. Khunti, "Differences in levels of physical activity between white and South Asian populations within a healthcare setting: impact of measurement type in a crosssectional study," BMJ Open, vol. 5, no. 7, article e006181, 2015.

[53] E. Bakhshi, J. Koohpayehzadeh, B. Seifi et al., "Obesity and related factors in Iran: the STEPS Survey, 2011," Iranian Red Crescent Medical Journal, vol. 17, no. 6, article e22479, 2015. 


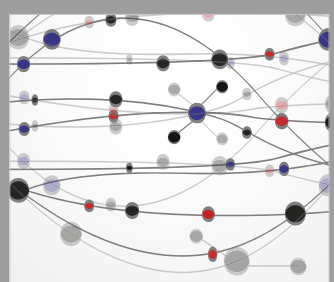

The Scientific World Journal
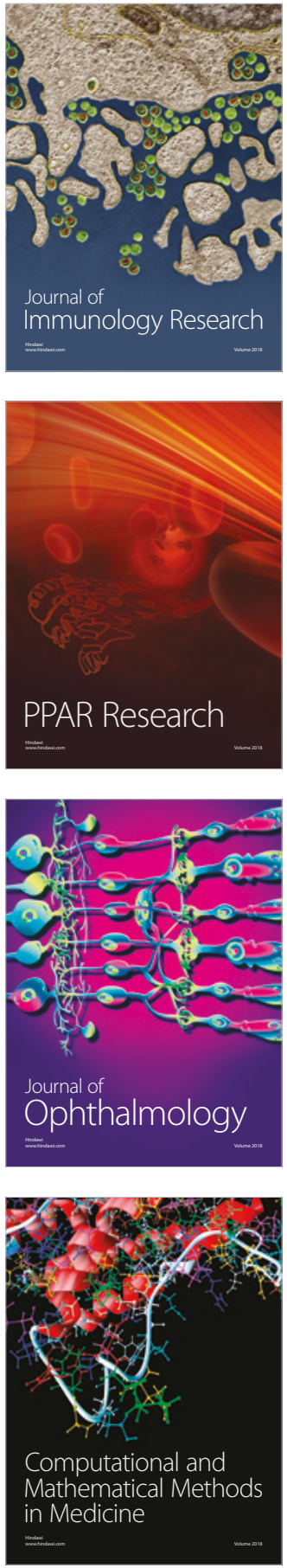

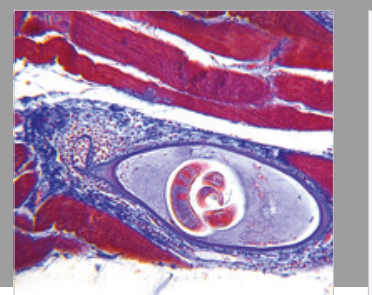

Gastroenterology Research and Practice

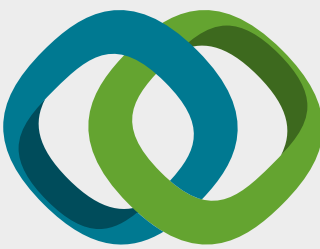

\section{Hindawi}

Submit your manuscripts at

www.hindawi.com
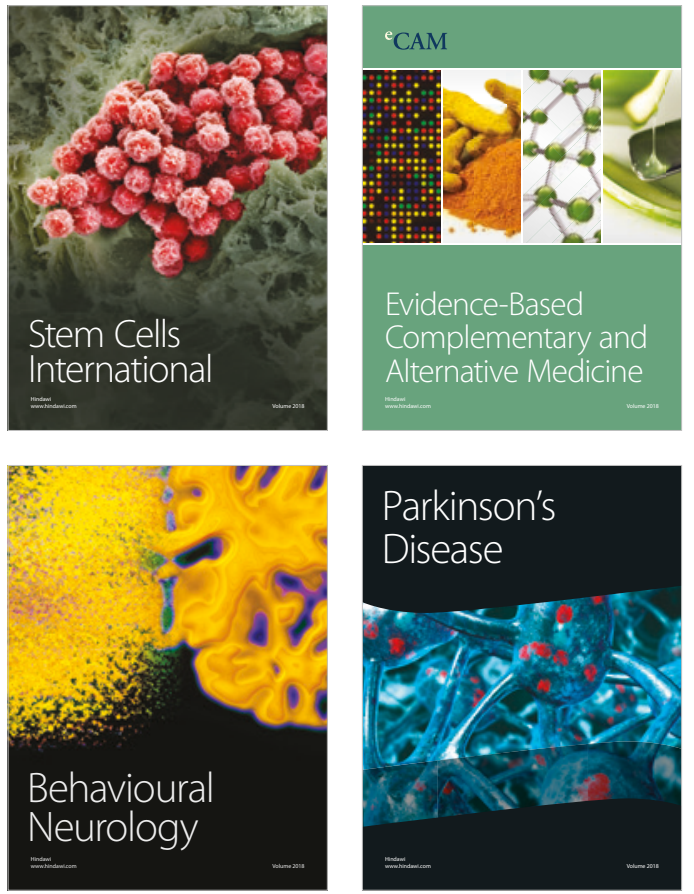

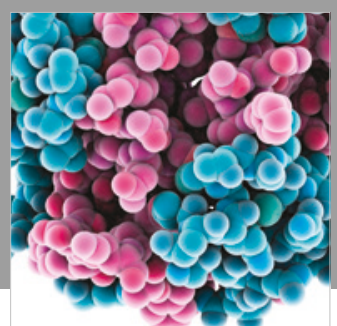

ournal of

Diabetes Research

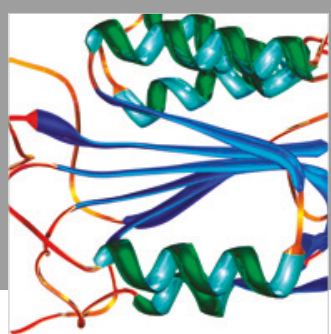

Disease Markers
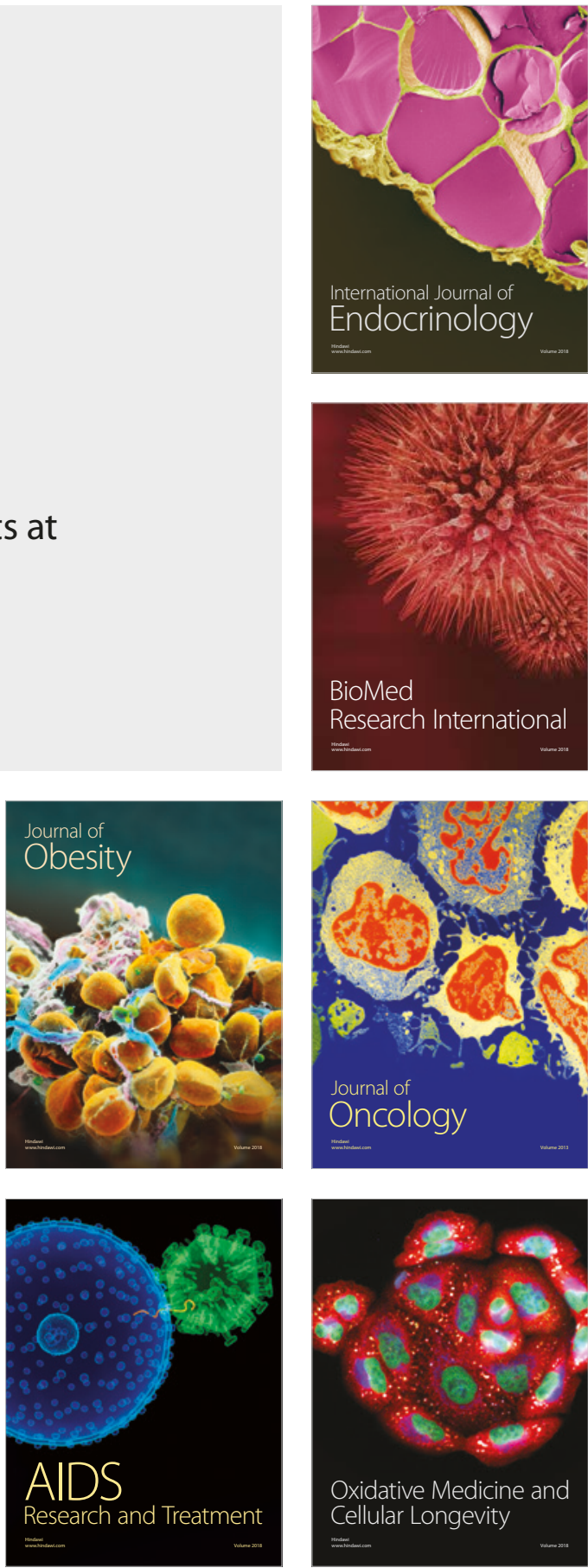